\title{
Consequences of chronic kidney disease in chronic obstructive pulmonary disease
}

\author{
Franziska C. Trudzinski ${ }^{1}$, Mohamad Alqudrah ${ }^{1}$, Albert Omlor', Stephen Zewinger², Danilo Fliser ${ }^{2}$, Timotheus Speer², \\ Frederik Seiler ${ }^{1}$, Frank Biertz ${ }^{3}$, Armin Koch³ ${ }^{3}$ Claus Vogelmeier ${ }^{4}$, Tobias Welte ${ }^{5}$, Henrik Watz ${ }^{6}$, Benjamin Waschki ${ }^{6}$, \\ Sebastian Fähndrich ${ }^{1}$, Rudolf Jörres ${ }^{7}$, Robert Bals ${ }^{1 *}$ and on behalf of the German COSYCONET consortium
}

\begin{abstract}
Background: The combination of chronic obstructive pulmonary disease (COPD) and chronic kidney disease (CKD) is associated with a higher prevalence of comorbidities and increased mortality. The impact of kidney function on patient-centered outcomes in COPD has not been evaluated.

Methods: Patients from the German COPD and Systemic Consequences - Comorbidities Network (COSYCONET) cohort COPD were analysed. CKD was diagnosed if the estimated glomerular filtration rate (eGFR) measurements were $<60 \mathrm{~mL} / \mathrm{min} / 1.73 \mathrm{~m}^{2}$ at study inclusion and six month later. The effect of CKD, on comorbidities, symptoms [modified British Medical Research Council dyspnoea scale], physical capacity [six-minute walk test, and timed up and go] and St George's Respiratory Questionnaire were analysed. Restricted cubic spline models were used to evaluate a nonlinear relationship between eGFR with patient-centered outcomes, cox survival analysis was applied to evaluate mortality.
\end{abstract}

Results: 2274 patients were analysed, with CKD diagnosed in 161 (7.1\%). Spline models adjusted for age, gender, $\mathrm{BMI}_{1} \mathrm{FEV}_{1}$ and cardiovascular comorbidities revealed independent associations between eGFR with modified British Medical Research Council dyspnoea scale, St George's Respiratory Questionnaire, $(p<0.001$ and $p=0.011)$, six-minute walk test $(p=0.015)$ and timed up and go $(p<0.001)$. CKD was associated with increased mortality, independently from for other cardiovascular comorbidities (hazard ratio 2.3; $p<0.001$ ).

Conclusion: These data show that CKD is a relevant comorbidity in COPD patients which impacts on patient-centered outcomes and mortality.

Trial registration: NCT01245933

Keywords: Chronic obstructive pulmonary disease, Chronic kidney disease, Patient-centered outcomes, Cohort study

\section{Introduction}

Chronic obstructive pulmonary disease (COPD) and chronic kidney disease (CKD) affect a large number of patients. The World Health Organization estimates COPD to become the 3rd leading cause of mortality worldwide in 2030 [1]. CKD, defined by abnormalities of kidney structure or function for more than 3 months [2], affected $14.8 \%$ of the U.S. adult general population in 2011-2014 [3]. Cigarette smoking and increasing age are risk factors for the development of both COPD and

\footnotetext{
* Correspondence: robert.bals@uks.eu

${ }^{1}$ Department of Internal Medicine V - Pulmonology, Allergology Critical Care

Care Medicine, Saarland University Hospital, Homburg, Germany

Full list of author information is available at the end of the article
}

CKD [4-6], with systemic inflammation as an extrapulmonary manifestation of COPD potentially increasing the risk of comorbid CKD [7]. This combination of COPD and CKD is independently associated with a higher prevalence of other comorbidities (especially cardiovascular) and increased mortality $[8,9]$.

The presence of a number of comorbidities has been shown to correlate with limitations of exercise capacity in COPD patients. Cardiovascular dysfunction is a wellknown predictor of a limited functional capacity and health status [10]. Whether CKD and kidney function have a role for functional limitations independent of established cardiovascular disease is currently unknown. The German COPD and Systemic Consequences - Comorbidities 
Network (COSYCONET) is a multicentre prospective cohort study investigating the interaction of COPD, comorbidities and systemic inflammation [11]. The present study aimed to analyse the relationship between COPD, CKD and estimated glomerular filtration rate (eGFR), focusing on patient-centered outcomes and mortality.

\section{Methods}

\section{Study population}

COSYCONET recruited patients age $\geq 40$ years and with a diagnosis of COPD or symptoms of chronic bronchitis who were available to attend repeated study visits up to 18 months. The characteristics of the cohort have been described previously [11]. A total of 2741 participants were recruited from September 2010 to December 2013 in 31 study centres throughout Germany. The present study analysed data from the baseline visit and the first follow-up at 6 months. Mortality was assessed until November 2017.

\section{Definition and staging of chronic kidney disease}

CKD was diagnosed by the estimated glomerular filtration rate, based on the Chronic Kidney Disease Epidemiology Collaboration (CKD-EPI) creatinine equation [12]. Patients with an eGFR $<60 \mathrm{~mL} / \mathrm{min} / 1.73 \mathrm{~m}^{2}$ at study inclusion and at the six month visit were considered as having CKD, as per the Kidney Disease Outcome Quality Initiative (KDOQI) guidelines [2]. CKD category 1 and 2 (eGFR $\geq 90$ and $60-89 \mathrm{~mL} / \mathrm{min} / 1.73 \mathrm{~m}^{2}$, respectively), reflecting normal or mildly decreased kidney function, were combined into the category 'no CKD'. CKD categories were defined as follows: CKD category $3 \mathrm{a}$ (eGFR $45-59 \mathrm{~mL} / \mathrm{min} / 1.73 \mathrm{~m}^{2}$ ), category $3 \mathrm{~b}$ (eGFR $30-44 \mathrm{~mL} / \mathrm{min} / 1.73 \mathrm{~m}^{2}$ ), category 4 (eGFR $15-29 \mathrm{~mL} / \mathrm{min} /$ $1.73 \mathrm{~m}^{2}$ ) and category 5 (eGFR $<15 \mathrm{~mL} / \mathrm{min} / 1.73 \mathrm{~m}^{2}$ ). Patients with missing laboratory values at one or both time points were excluded from the first part of the present analyses.

\section{Pulmonary function, GOLD classification}

All pulmonary function tests (i.e. forced spirometry, body plethysmography and diffusion capacity) were performed $45 \mathrm{~min}$ after inhalation of $400 \mu \mathrm{g}$ salbutamol and $80 \mu \mathrm{g}$ ipratropium bromide according to current recommendations [13-17].

Due to the above mentioned inclusion criteria there were also some patients with a $\mathrm{FEV}_{1} / \mathrm{FVC}$ ratio above $70 \%$ at baseline. These patients were described as GOLD Stage 0 . This group was defined as having a $\mathrm{FEV}_{1} / \mathrm{FVC}$ ratio $>70 \%$ and (i) having a doctor's diagnosis of chronic bronchitis and/or (ii) indicating a severity of cough of at least 3 in the respective COPD Assessment Test (CAT) item and/or (iii) indicating a severity of phlegm of at least 3 in the respective CAT item [11].

\section{Comorbidities}

All participants underwent structured interviews to identify other comorbidities. The overall comorbid burden was summarised in a main comorbidity index (MCI). The MCI depicts a non-weighted summary score of the 34 following conditions: allergic diseases, arrhythmia, asthma, cancer, cirrhosis of the liver, coronary artery disease, chronic bronchitis, epilepsy, gastritis, gastroesophageal reflux, gout, heart failure, hepatitis, hypertension, hypothyroidism, hyperthyroidism or hyperparathyroidism, mental disorders, insulin-dependent diabetes mellitus, multiple sclerosis, myocardial infarction, non-insulin-dependent diabetes mellitus, osteoarthrosis, osteoarthritis, osteoporosis, peptic ulcer, parkinson disease, peripheral artery disease, peripheral neuropathy, pulmonary fibrosis, renal colic or renal calculi, sarcoidosis, sleep apnea, stroke and venous thrombosis. The MCI was calculated by counting each item with 1 point. A summarised assessment of cardiovascular comorbidity was performed in a similar manner using the cardiovascular index (CVI), which includes the five cardiovascular items hypertension, coronary artery disease, myocardial infarction, arrhythmia and stroke. Patients with a CVI of $\geq 1$ point were considered as having cardiovascular comorbidities.

\section{Measurements of symptoms, functional status, exercise capacity and health status}

Severity of dyspnoea was assessed using the modified British Medical Research Council dyspnoea scale (mMRC) [18]. The COPD related symptom load was assessed by the COPD Assessment Test (CAT) [19]. Functional status and exercise capacity were assessed by the timed up and go' (TuG) and the six-minute walk test (6MWT). The 'timed up and go' measures the time taken for the patient to rise from a chair, walk $3 \mathrm{~m}$, turn, walk back, and sit down again [20]. The six-minute walk test was performed as described in the former American Thoracic Society (ATS) guidelines [21]. COPD specific health status was measured by the St George's Respiratory Questionnaire (SGRQ) [22]. Quality of life was measured by the EuroQoL 5-dimension (EQ-5D) Questionnaire.

\section{Statistical analysis}

The association of CKD with functional, laboratory values and other comorbidities were analyzed using group comparisons. We described categorical data using frequencies and percentages. For continuous data we used means (standard deviations), those values which were markedly different from normal distribution are presented as median (interquartile range). Comparisons between the "CKD and the 'no CKD' group were performed by Fisher's exact test or $\mathrm{X}^{2}$ test, as appropriate in case of categorical variables, t-tests or Wilcoxon test were used for continuous variables as appropriate. 
Multivariate regression models with included established risk factors (e.g. age, sex, BMI, FEV1\% pred.) were used for analysis of the impact of CKD for different numeric variables. Analysis was performed in SAS 9.3 and results were considered statistically significant for $P$ values less than 0.05. Because of the non-linear association between mMRC, TuG, 6MWT, SGRQ, FEV1, BMI and eGFR, we analyzed non-linear associations between the aforementioned parameters and eGFR from the first visit by using restricted cubic splines of eGFR with three knots. Knots were placed at $59.6 \mathrm{ml} / \mathrm{min}, 84.8 \mathrm{ml} / \mathrm{min}$, and $100.8 \mathrm{ml} /$ min which corresponds to the 10th, 50th, and 90th percentile of the eGFR values. Analyses were adjusted for age, sex, BMI, FEV1 (\% pred.) and CVI score, where appropriate. Analyses were performed using STATA IC 15. Multivariate adjusted restricted cubic spline analyses were performed using the STATA package 'postrcspline'. Cox analysis was used to characterize the impact of CKD on mortality with additional independent variables: BMI, sex, CVI, and FEV1\% pred. Analysis was performed using SPSS version 24 (IBM, Armonk NY, USA).

\section{Results}

\section{Study subjects and prevalence of CKD}

After screening of all 2741 patients from the COSYCONET study cohort, 2274 were eligible for analysis of CKD. 467 patients with missing laboratory values at one or both of the two defined time points were excluded from the CKD part of the analysis. CKD was diagnosed in 161 of 2274 patients (7.1\%). The majority of all patients $(60.6 \%)$ were male, and the mean \pm SD age was $65.0 \pm 8.4$ years. Among the 161 patients with CKD, 114 (70.8\%) were category $3 \mathrm{~A}, 43(26.7 \%)$ were category $3 \mathrm{~B}$, and $4(2.5 \%)$ were category 4 . There were no patients with an eGRF $<15 \mathrm{~mL} / \mathrm{min} / 1.73 \mathrm{~m}^{2}$ or on Dialysis. The distribution of chronic kidney disease categories in the study population is presented in Table 1 .

Table 1 Distribution of chronic kidney disease categories in the study population

\begin{tabular}{llll}
\hline Kidney function & $\begin{array}{l}\text { CKD } \\
\text { categories }\end{array}$ & eGFR (mL) & $\begin{array}{l}\text { No. of } \\
\text { Patients (\%) }\end{array}$ \\
\hline $\begin{array}{l}\text { normal to mild } \\
\text { reduced }\end{array}$ & $1-2$ & $>60$ & $2113(92.9)$ \\
moderate reduced & 3A & $45-59$ & $114(5.0)$ \\
& $3 B$ & $20-44$ & $43(1.9)$ \\
severely reduced & 4 & $15-29$ & $4(0.2)$ \\
kidney failure & 5 & $<15$ or on Dialysis & $0(0)$
\end{tabular}

CKD categories were defined in accordance with the National Kidney Foundation-Kidney Disease Outcomes Quality Initiative (KDOQI) guideline Abbreviations: CKD Chronic Kidney Disease; eGFR estimated Glomerular Filtration Rate

\section{Patients characteristics}

Patients with CKD were significantly older and had a significantly higher BMI than those with normal or mildly reduced kidney function (i.e. the 'no CKD' group) (Table 2). Compared with the 'no CKD' group, patients with CKD showed less residual volume, and were more likely to be classified to be in the lower GOLD stages (0.0073). There were no differences between the two groups in terms of other spirometric parameters, diffusion capacity, or oxygenation. The characteristics of the study population are presented in Table 2 .

\section{Comorbidity burden}

Self-reported comorbidities were more frequent in the CKD group, in particular cardio- and cerebrovascular disease, peripheral artery disease (PAD), diabetes, gout and malignancies (Table 3). Furthermore, compared to the 'no CKD' group, patients with CKD were more likely to have higher CVI and MCI scores.

\section{Laboratory testing}

Haemoglobin was significant lower in patients with CKD compared with the 'no CKD' group. CKD patients presented significantly elevated blood glucose and glycosylated haemoglobin compared to the no CKD' group. There were no differences between the two groups in term of leucocytes, C-reactive protein or cholesterol. Laboratory findings are summarized in the Additional file 1: Table S1.

\section{Measurements of symptoms, functional status, exercise capacity and health status}

Patients with CKD had a significant higher mMRC values as compared to the 'no CKD' group. The COPD related symptom load as measured by the CAT showed no differences between the two groups (Table 4). Functional status and exercise capacity were reduced in CKD patients as they took significantly longer to complete the TuG as compared to the 'no CKD' group and the distance walked in 6 min was significantly shorter. COPD specific health status and quality of life showed no differences between the two groups (Table 4). Multivariate regression models with included established risk factors (e.g. age, sex, BMI, FEV1\%pred) were used for analysis of the impact of CKD for different numeric variables (dyspnoea, functional status, exercise capacity and QOL). The effect of CKD on the distance walked in $6 \mathrm{~min}$ was independent from the effect of age, gender, BMI, FEV1 and CVI (point estimate, $17.6 \mathrm{~m} ; 95 \%$ confidence interval, $0.8-34.4, p<.0001)$.

\section{Restricted cubic spline models}

Spline models adjusted for age, sex, BMI, FEV1 (\% pred.) and cardiovascular comorbidity (CVI score) were performed to analyse the non-linear association of eGFR 
Table 2 Patient characteristics

\begin{tabular}{|c|c|c|c|c|c|}
\hline & $\mathrm{N}$ & All & No CKD & CKD & $p$ value \\
\hline Age (years) & 2274 & $65.0 \pm 8.4$ & $64.5 \pm 8.3$ & $72.2 \pm 6.6$ & $<0.0001$ \\
\hline Male & 2274 & $1378(60.6 \%)$ & $1280(60.6 \%)$ & 98 (60.9\%) & 0.9471 \\
\hline BMI $\left(\mathrm{kg} / \mathrm{m}^{2}\right)$ & 2272 & $27.2 \pm 5.2$ & $27.00 \pm 5.2$ & $28.7 \pm 5.3$ & $<0.0001$ \\
\hline Smoking history (PY) a & 2192 & $40.0[16.5-63.8]$ & 39.0 [16.5-63.0] & $51.3 \pm 43.3$ & 0.0793 \\
\hline \multicolumn{6}{|l|}{ Lung function } \\
\hline FVC (L) & 2256 & $3.0 \pm 1.0$ & $3.0 \pm 1.0$ & $2.9 \pm 0.9$ & 0.1660 \\
\hline FVC (\%pred) & 2256 & $78.6 \pm 18.9$ & $78.7 \pm 18.9$ & $77.4 \pm 18.4$ & 0.3875 \\
\hline $\mathrm{FEV}_{1}(\mathrm{~L})^{\mathrm{a}}$ & 2260 & $16[1.1-2.1]$ & $1.6[1.2-2.1]$ & $1.5[1.1-2.0]$ & 0.3162 \\
\hline $\mathrm{FEV}_{1}$ (\%pred) & 2260 & $57.0 \pm 21.0$ & $57.0 \pm 20.9$ & $56.6 \pm 22.4$ & 0.7416 \\
\hline ITGV (L) & 2205 & $4.7 \pm 1.3$ & $4.7 \pm 1.3$ & $4.7 \pm 1.3$ & 0.4425 \\
\hline ITGV (\%pred) & 2205 & $143.5 \pm 37.7$ & $143.2 \pm 37.5$ & $147.1 \pm 39.6$ & 0.2098 \\
\hline RV (L) & 2194 & $3.8 \pm 1.23$ & $3.8 \pm 1.2$ & $3.9 \pm 1.3$ & 0.1667 \\
\hline RV (\%pred) & 2134 & $167.42 \pm 58.6$ & $168.2 \pm 58.8$ & $156.1 \pm 54.5$ & 0.0143 \\
\hline TLC (L) & 2189 & $7.1 \pm 1.5$ & $7.1 \pm 1.5$ & $7.1 \pm 1.4$ & 0.7341 \\
\hline TLC (\%pred) & 2189 & $115.5 \pm 20.3$ & $115.3 \pm 20.2$ & $117.9 \pm 21.3$ & 0.1474 \\
\hline TLCO (\%) & 2146 & $55.7 \pm 21.8$ & $55.9 \pm 21.7$ & $55.4 \pm 23.1$ & 0.7861 \\
\hline \multicolumn{6}{|l|}{ GOLD Classification } \\
\hline Stage 0 & 2260 & $363(16.1)$ & $333(15.8)$ & 30 (18.6) & 0.0073 \\
\hline Stage I & 2260 & $182(8.1)$ & $166(7.9)$ & $16(9.9)$ & \\
\hline Stage II & 2260 & $831(36.7)$ & 760 (36.2) & $71(44.10)$ & \\
\hline Stage III & 2260 & $706(31.2)$ & $666(31.8)$ & $40(24.8)$ & \\
\hline Stage IV & 2260 & $178(7.9)$ & $174(8.3)$ & $4(2.5)$ & \\
\hline \multicolumn{6}{|l|}{ Blood gas analysis } \\
\hline $\mathrm{pH}$ value & 2213 & $7.4 \pm 0.1$ & $7.4 \pm 0.1$ & $7.4 \pm 0.0$ & 0.3847 \\
\hline $\mathrm{PaO}_{2}(\mathrm{mmHg})$ & 2212 & $67.4 \pm 9.2$ & $67.3 \pm 9.1$ & $68.5 \pm 10.8$ & 0.1792 \\
\hline $\mathrm{PaCO}_{2}(\mathrm{mmHg})$ & 2212 & $37.7 \pm 4.9$ & $37.7 \pm 4.9$ & $37.6 \pm 4.6$ & 0.7490 \\
\hline $\mathrm{HCO} 3$ (mmol/L) & 2211 & $24.3 \pm 2.9$ & $24.2 \pm 2.9$ & $24.4 \pm 2.8$ & 0.6371 \\
\hline
\end{tabular}

Values are presented as mean \pm standard deviations or number (\%). Those values which were markedly different from normal distribution $\left({ }^{\mathrm{a}}\right)$ are presented as median [interquartile range]. $p \leq 0.05$ was considered statistically significant (bold)

Abbreviations: $B M I$ body mass index, $P Y$ pack-years, FEV1 forced expiratory volume in $1 \mathrm{~s}, R V$ residual volume, $T L C$ total lung capacity, ITGV intrathoracic gas volume, $T L C O$ transfer factor for carbon monoxide

with dyspnea, functional status (FS), exercise capacity (EC) and quality of life (QoL). These models revealed independent relationships of eGFR with mMRC, TuG, 6MWT, and SGRQ. Figure 1a and d show eGFR as an independent predictor of mMRC $(p<0.001)$ and SGRQ $(p=0.011)$ with $\mathrm{j}$-shaped associations. Figure $1 \mathrm{c}$ shows an $\mathrm{u}$-shaped relationship of eGFR with 6MWT ( $<<0.001)$, while the association of eGFR with the timed up and go is reverse $j$-shaped $(p=0.015$, Fig. $1 \mathrm{~b})$. Figure 1e and $\mathrm{f}$ show spline plots for the association of eGFR with FEV1 (\% pred.) and BMI adjusted for age, sex, cardiovascular comorbidity (CVI score) and either BMI or FEV1 (\% pred.). These models reveal an association of lower FEV1\% pred. and BMI with higher eGFR values ( $P=0.003$ and 0.001 respectively)

\section{Impact of CKD mortality}

To investigate whether COPD patients with comorbid CKD have an increased risk of dying, we performed Cox regression analysis with age, BMI, sex, packyears, CVI, and FEV1\% pred. as cofounders and found that CKD is significantly associated with increased mortality (Fig. 2). This association was stable also from models that included the individual comorbidities or risk factors (data not shown). The hazard ratios (confidence intervals, $p$ value) were: CKD, 2.35 (1.52-3.63, $\mathrm{p}=<0.001$ ); sex (male) 1.49 $(1.03-2.14, p=0.032)$, FEV1\% pred. 0.96 (0.95-0.97, $p=0.000)$; age $1.09(1.06-1.11, \mathrm{p}=0.000)$. No significance was found for CVI and BMI.

\section{Discussion}

The present study characterized patients with comorbid COPD and CKD from the German COSYCONET study cohort. This is to our knowledge the first study analysing the effects of comorbid CKD on patient-centered outcomes in COPD. COPD Patients with CKD were more likely to have additional comorbidities, reported increased 
Table 3 Selected self-reported comorbidities

\begin{tabular}{|c|c|c|c|c|c|}
\hline comorbidities & $\mathrm{N}$ & All & No CKD & CKD & $p$ value \\
\hline Hypertension & 2206 & $1227(55.7)$ & $1112(54.32)$ & $115(74.2)$ & $<0.0001$ \\
\hline CAD & 2200 & $343(15.7)$ & $306(15.0)$ & $39(25.2)$ & 0.0008 \\
\hline $\mathrm{Ml}$ & 2202 & $182(8.3)$ & $162(7.9)$ & $20(12.9)$ & 0.0315 \\
\hline Arrhythmia & 1183 & $196(16.7)$ & $168(15.2)$ & $28(36.8)$ & $<0.0001$ \\
\hline Heart failure & 1182 & $118(10)$ & $101(9.1)$ & $17(22.4)$ & 0.0003 \\
\hline Stroke & 2202 & $92(4.2)$ & $80(3.9)$ & $12(7.7)$ & 0.0242 \\
\hline PAD & 2202 & 255 (11.6) & $226(11.0)$ & $29(18.7)$ & 0.0046 \\
\hline DM & 2202 & $111(5.0)$ & $92(4.5)$ & $19(12.3)$ & $<0.0001$ \\
\hline Gout & 2202 & $380(17.2)$ & $320(15.6)$ & $60(38.7)$ & $<0.0001$ \\
\hline Malignant tumour & 2202 & $256(11.6)$ & $226(11.0)$ & $31(20.0)$ & 0.0009 \\
\hline Osteoporosis & 2201 & $320(14.5)$ & $290(14.1)$ & $30(19.4)$ & 0.0787 \\
\hline Pathologic fracture & 2202 & $100(4.5)$ & $93(4.5)$ & $7(4.5)$ & 0.9876 \\
\hline CVI $(\geq 1)$ & 2274 & $1398(63.4)$ & $1315(62.2)$ & $129(80.1)$ & $<0.0001$ \\
\hline $\mathrm{MCl}(\geq 5)$ & 2274 & $1045(47.4)$ & $961(45.9)$ & 109 (67.4) & $<0.0001$ \\
\hline
\end{tabular}

Abbreviations: CAD coronary artery disease, MI myocardial infarction, PAD peripheral artery disease, DM Type I and Type II diabetes mellitus using insulin, CVI cardiovascular index, $M C I$ main comorbidity index. Values are presented number (\%). $p \leq 0.05$ was considered statistically significant (bold)

dyspnea, and had a significantly reduced exercise capacity compared with the 'no CKD' group. Spline models adjusted for age, gender, BMI, FEV1 (\% pred.) and cardiovascular comorbidity revealed independent nonlinear associations of eGFR with dyspnoea, functional status, exercise capacity and health status. CKD was furthermore a predictor for mortality independently from other cardiovascular comorbidities.

There are several studies focusing on the prevalence of CKD in patients with COPD, conducted in a range of populations [23-29]. Most of these studies are singlecenter studys with a small sample size One recent metaanalysis by Gaddam and colleagues showed an increased

Table 4 Measurement of dyspnoea, COPD specific health status, quality of life, exercise capacity and physical activity

\begin{tabular}{|c|c|c|c|c|c|}
\hline & $\mathrm{N}$ & All & No CKD & CKD & $p$ value \\
\hline $\mathrm{mMRC}$ & 2260 & & & & $<0.0001$ \\
\hline 0 & & $207(9.2)$ & $196(9.3)$ & $12(7.5)$ & \\
\hline 1 & & $1067(47.2)$ & $1014(48.3)$ & $53(32.9)$ & \\
\hline 2 & & $614(27.2)$ & $557(26.5)$ & $57(35.4)$ & \\
\hline 3 & & 353 (15.6) & 317 (15.1) & $36(22.4)$ & \\
\hline 4 & & $19(0.9)$ & $16(0.8)$ & $3(1.9)$ & \\
\hline CAT & 2263 & $17.8 \pm 7.2$ & $17.8 \pm 7.2$ & $17.4 \pm 7.0$ & 0.5117 \\
\hline SGRQ & 2259 & $41.7 \pm 19.6$ & $41.5 \pm 19.5$ & $44.0 \pm 19.9$ & 0.1196 \\
\hline EQ 5D & 2266 & $0.8 \pm 0.2$ & $0.8 \pm 0.2$ & $0.8 \pm 0.2$ & 0.6427 \\
\hline 6MWD & 2225 & $424.7 \pm 105.2$ & $427.6 \pm 104.3$ & $385.9 \pm 110.1$ & $<0.0001$ \\
\hline TuG (sec.) & 2224 & $6.9 \pm 2.2$ & $6.9 \pm 2.2$ & $7.5 \pm 2.4$ & 0.0004 \\
\hline
\end{tabular}

Abbreviations: $m M R C$ Modified British Medical Research Council dyspnoea scale, CAT COPD Assessment Test, 6-MWD Six minute walk distance, SGRQ St George's Respiratory Questionnaire, EQ-5D EuroQol- 5 dimension. Values are presented as $\mathrm{N}(\%)$ or mean $\pm \mathrm{SD} . p \leq 0.05$ was considered statistically significant (bold) prevalence of CKD in patients with COPD even after adjustment for co-variates including age, gender, BMI and smoking status, thus suggesting an independent association of CKD with COPD [30]. The overall CKD prevalence in our study population was $7.1 \%$. This finding is consistent with that in other COPD populations reporting a CKD prevalence of $4-8 \%$ [23, 25, 29]. Systemic inflammation might be one linking element between these two conditions [7].

In the present study, mMRC scores were higher in patients with CKD and spline interpolations revealed an independent inverse association of eGFR with mMRC. Increased mMRC values in turn are linked with reduced physical activity levels in patients with COPD [31]. The higher level of dyspnoea in patients with comorbid CKD and COPD was also associated with reduced exercise capacity as measured by the six minute walk test. Spline interpolations for the association of eGFR with 6MWD distance showed a linear independent association if eGFR values were below $60 \mathrm{ml} / \mathrm{min} / 1,73 \mathrm{~m}^{2}$. This relationship was also shown for eGFR and COPD specific health status measured by the SGRQ if kidney function were reduced. However those patients with normal kidney function showed mixed outcomes for mMRC, timed up and go, six minute walk test and SGRQ. Especially those patients with high eGFR $\left(>90 \mathrm{ml} / \mathrm{min} / 1.73 \mathrm{~m}^{2}\right)$ values presented more symptoms and inferior performance. The combination of high eGFR values and unfavourable outcomes in apparently healthy subjects was described as renal hyperfiltratration $(\mathrm{RH})$. The pathogenesis of $\mathrm{RH}$ is still poorly understood, but there are associations with hypertension, diabetes, obesity and smoking [32]. Renal hyperfiltratration was shown as 


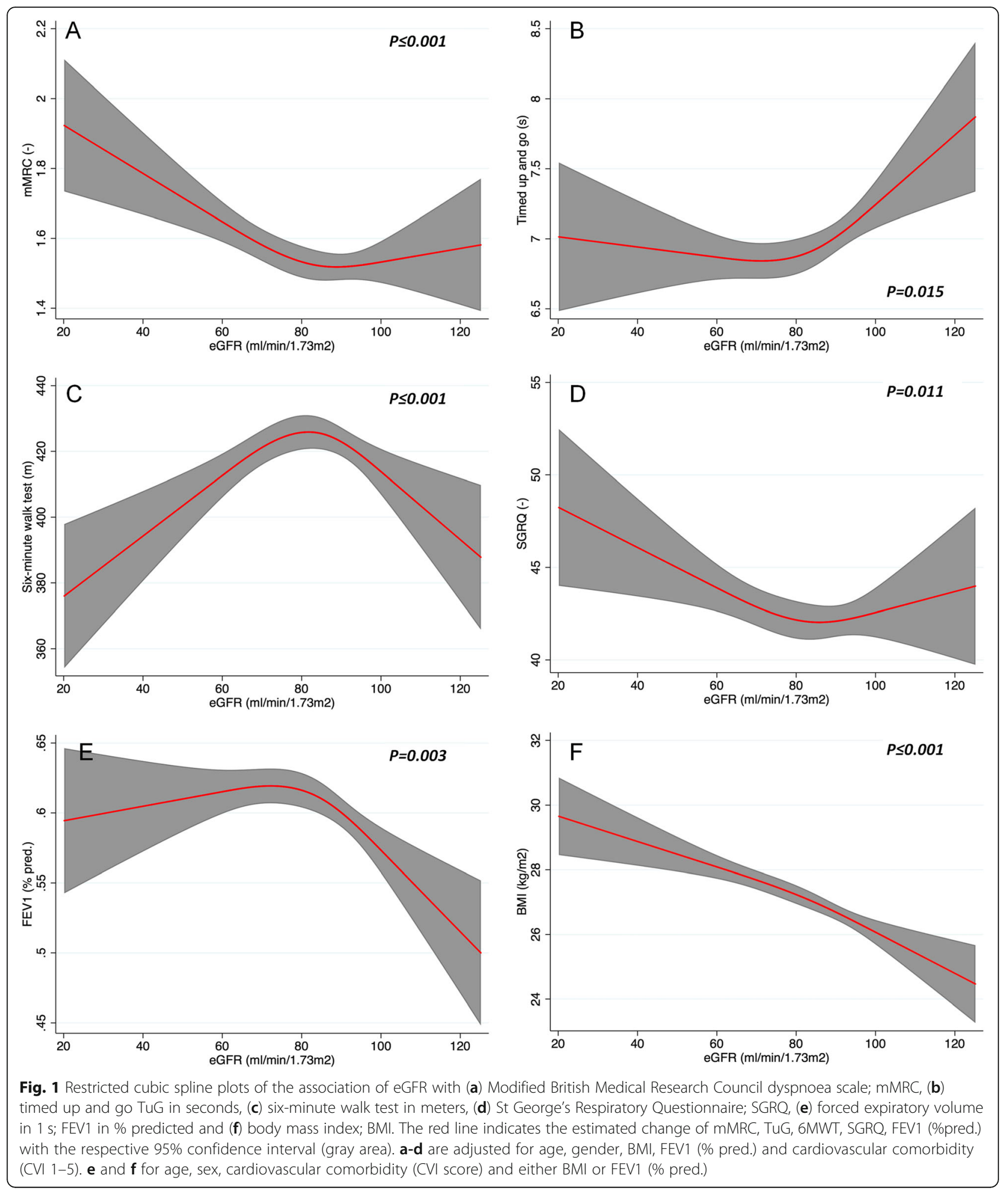

an independent predictor of chronic cardiopulmonary diseases and all-cause mortality [33]. This is commonly regarded as an overestimation of GFR because of muscle wasting in a high risk group. Our data support this theory as low $\mathrm{FEV}_{1}$ and BMI were independently associated with high eGFR values in our cohort. COPD related inactivity and sarcopenia might be on explanation for these findings, however the BMI values were still in the normal range and the BMI includes no information on body composition. 


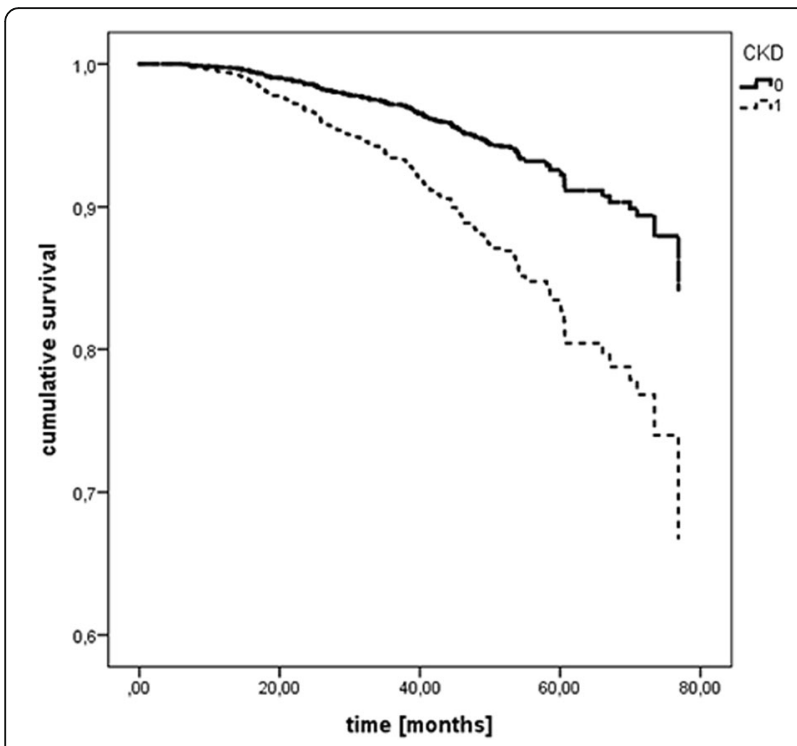

Fig. 2 Cox analysis with BMI, sex, packyears, CVI, and FEV1\% pred. as cofounders showed that CKD is significantly associated with mortality

We also assessed whether CKD is associated with increased mortality. CKD is closely associated with cardiovascular diseases and an independent risk factor for death [34, 35]. This finding is in agreement with earlier studies that used health care system data $[8,36]$ and showed that COPD increased risk of death in CKD patients. CKD also increases the mortality risk in patients with acute exacerbations of COPD [37]. Our study suggests that these negative outcomes might be mediated by an impact of CKD on symptoms, functional status and exercise capacity. The effects of CKD on exercise capacity cannot simply be explained by the higher frequency of these comorbidities, but suggest that CKD per se has a negative effect on exercise capacity. The underlying mechanisms for this finding are likely complex and include increased systemic inflammation, (patho-)physiological interaction between lung and kidney, or network effects between several comorbidities including cardiovascular diseases. CKD contributes substantially to other common systemic manifestations of COPD such as malnutrition, muscle wasting, anaemia [38], osteoporosis and cardiovascular disease [38, 39], which in total negatively affect exercise capacity [21] and therefore, might explain the results of our study.

The present study has some limitations: The presence of comorbidities was based on patients' reports. Other limitations are mainly related to the limited sample size in the CKD categories. The majority of patients within this category had only moderate kidney impairment, probably because these are the ones that are more willing to participate into cohorts, which might lead to a selection bias.

Our results from eGFR spline interpolations suggest that there is an increasing impact on dyspnoea, exercise capacity and health status with increasing kidney impairment. We therefore speculate that a higher proportion of CKD category 4 and 5 patients would have led to more pronounced differences between the two categories.

\section{Conclusion}

CKD is a frequent finding in COPD patients and possibly an important contributor to the comorbidome of the disease as well as to many important disease outcomes, including mortality. Spline models showed a nonlinear association of eGFR on different patient-centered outcomes, CKD but also high eGFR values might be predictors for inactivity and progressive deconditioning in COPD. Interventions that increase physical activity levels might play a key role to improve outcomes in these special groups of patients. CKD is therefore a relevant COPD comorbidity, and there is an urgent need for more information to improve outcome in this high risk group of patients.

\section{Additional file}

Additional file 1: Table S1. Laboratory values. (DOCX 18 kb)

\section{Abbreviations}

6MWT: Six-minute walk test; BMI: Body mass index; CAD: Coronary artery disease; CAT: COPD assessment test; CKD: Chronic kidney disease; CKDEPI: Chronic kidney disease epidemiology collaboration; COPD: Chronic obstructive pulmonary disease; CRP: C-reactive protein; CVI: Cardiovascular index; DM: Diabetes mellitus; EC: Exercise capacity; eGFR: Estimated glomerular filtration rate; EQ-5D: EuroQol- 5 dimension; FEV ${ }_{1}$ : Forced expiratory volume in $1 \mathrm{~s}$; FS: Functional status; HbA1c: Glycosylated haemoglobin; HDL: High density lipoprotein; ITGV: Intrathoracic gas volume; KDOQI: National kidney foundation-kidney disease outcomes quality Initiative; LDL: Low density lipoprotein; MCl: Main comorbidity index; MI: Myocardial infarction; mMRC: Modified british medical research council dyspnoea scale; PAD: Peripheral artery disease; PY: Pack-years; QoL: Quality of life; RV: Residual volume; SGRQ: St George's Respiratory Questionnaire; TLC: Total lung capacity; TLCO: Transfer factor for carbon monoxide.; TuG: Timed up and go

\section{Acknowledgments}

The authors thank David Young of Young Medical Communications and Consulting Ltd. for his critical review of the manuscript and all investigators and study centers who contributed in patient recruitment and data collection as listed on http://www.asconet.net/html/cosyconet/studzent.

\section{Authors' contributions}

FCT and RB, FB, MA and TS contributed to conception of the study, to data analysis and interpretation and drafted the manuscript AK, CV, TW, HW, BW, $\mathrm{SF}$ and $\mathrm{RJ}$ and $\mathrm{RB}$ contributed to data collection, data interpretation and revised the manuscript critically for important intellectual content. AO, SZ, and DF and FS contributed to data interpretation and revised the manuscript critically for important intellectual content. All authors approved the final version of the manuscript.

\section{Funding}

This work was supported by the Competence Network Asthma and COPD (ASCONET). The COSYCONET COPD Cohort is funded by the German Federal Ministry of Education and Research (BMBF) with grant numbers $01 \mathrm{Gl0881}$ and 01GI0882, as well as by unrestricted grants from AstraZeneca $\mathrm{GmbH}$, Bayer Schering Pharma AG, Boehringer Ingelheim Pharma GmbH \& Co. KG, Chiesi GmbH, GlaxoSmithKline, Grifols Deutschland GmbH, MSD Sharp \& Dohme $\mathrm{GmbH}$, Mundipharma $\mathrm{GmbH}$, Novartis Deutschland $\mathrm{GmbH}$, Pfizer 
Pharma GmbH, Takeda Pharma Vertrieb GmbH \& Co. KG for patient investigations and laboratory measurements.

\section{Availability of data and materials}

The data are part of the German COPD cohort COSYCONET (http://www. asconet.net) and available upon request.

\section{Ethics approval and consent to participate}

The COSYCONET study has been approved by the ethics committee of the medical faculty of the Philipps-Universität Marburg, the local ethics committees of the participating centers (a list of all participating study centers can be found here: http://www.asconet.net/html/cosyconet/studzent) and by the concerned data security authority (data security agency of the federal states of Hessen, Baden-Württemberg, Lower-Saxony, and Saarland).

\section{Consent for publication}

All cohort participants gave their written informed consent and agreed to the scientific evaluation and publication of the collected data.

\section{Competing interests}

The authors declare that they have no competing interests.

\section{Author details}

Department of Internal Medicine V - Pulmonology, Allergology Critical Care Care Medicine, Saarland University Hospital, Homburg, Germany. ${ }^{2}$ Department of Internal Medicine IV - Nephrology, Saarland University Hospital, Homburg, Germany. ${ }^{3}$ Institute for Biostatistics, Hannover Medical School, Hannover, Germany. ${ }^{4}$ Department of Medicine, Pulmonary and Critical Care Medicine, University Medical Center Giessen and Marburg, Philipps-University Marburg, Member of the German Center for Lung Research (DZL), Marburg, Germany. ${ }^{5}$ Clinic for Pneumology Hannover Medical School, Member of the German Center for Lung Research, Hannover, Germany. ${ }^{6}$ Pulmonary Research Institute at LungenClinic Grosshansdorf Airway Research Center North, Member of the German Center for Lung Research, Grosshansdorf, Germany. ${ }^{7}$ Institute and Outpatient Clinic for Occupational, Social and Environmental Medicine, Munich, Germany.

Received: 22 September 2018 Accepted: 20 June 2019

Published online: 12 July 2019

\section{References}

1. Available from: http://www.who.int/respiratory/copd/burden/en/. Accessed 7 July 2019.

2. Inker LA, Astor BC, Fox CH, Isakova T, Lash JP, Peralta CA, et al. KDOQI US commentary on the $2012 \mathrm{KDIGO}$ clinical practice guideline for the evaluation and management of CKD. Am J Kidney Dis. 2014;63(5):713-35.

3. Saran R, Robinson B, Abbott KC, Agodoa LY, Albertus P, Ayanian J, et al. US renal data system 2016 annual data report: epidemiology of kidney disease in the United States. Am J Kidney Dis. 2017;69(3 Suppl 1):A7-8.

4. Vogelmeier CF, Criner GJ, Martinez FJ, Anzueto A, Barnes PJ, Bourbeau J, et al. Global strategy for the diagnosis, management, and prevention of chronic obstructive lung disease 2017 report: GOLD executive summary. Eur Respir J. 2017:49(3):1-32.

5. Haroun MK, Jaar BG, Hoffman SC, Comstock GW, Klag MJ, Coresh J. Risk factors for chronic kidney disease: a prospective study of 23,534 men and women in Washington County. Maryland J Am Soc Nephrol. 2003;14(11):2934-41.

6. Fox CS, Larson MG, Leip EP, Culleton B, PWF W, Levy D. Predictors of newonset kidney disease in a community-based population. J Am Med Assoc. 2004;291(7):844-50.

7. Miyamoto T, Carrero JJ, Stenvinkel P. Inflammation as a risk factor and target for therapy in chronic kidney disease. Curr Opin Nephrol Hypertens. 2011;20(6):662-8.

8. Navaneethan SD, Schold JD, Huang H, Nakhoul G, Jolly SE, Arrigain S, et al. Mortality outcomes of patients with chronic kidney disease and chronic obstructive pulmonary disease. Am J Nephrol. 2016;43(1):39-46.

9. van Gestel YR, Chonchol M, Hoeks SE, Welten GM, Stam H, Mertens FW, et al. Association between chronic obstructive pulmonary disease and chronic kidney disease in vascular surgery patients. Nephrol Dial Transplant. 2009; 24(9):2763-7.
10. Houben-Wilke S, Jorres RA, Bals R, Franssen FM, Glaser S, Holle R, et al. Peripheral artery disease and its clinical relevance in patients with chronic obstructive pulmonary disease in the COPD and systemic consequencescomorbidities network study. Am J Respir Crit Care Med. 2017:195(2):189-97.

11. Karch A, Vogelmeier C, Welte T, Bals R, Kauczor HU, Biederer J, et al. The German COPD cohort COSYCONET: aims, methods and descriptive analysis of the study population at baseline. Respir Med. 2016;114:27-37.

12. Levey AS, Stevens LA, Schmid CH, Zhang YL, Castro AF 3rd, Feldman HI, et al. A new equation to estimate glomerular filtration rate. Ann Intern Med. 2009;150(9):604-12.

13. Miller MR, Hankinson J, Brusasco V, Burgos F, Casaburi R, Coates A, et al. Standardisation of spirometry. Eur Respir J. 2005;26(2):319-38,

14. Criee CP, Berdel D, Heise D, Kardos P, Kohler D, Leupold W, et al. Recommendations on spirometry by Deutsche AtemwegsligaPneumologie. 2006:60(9):576-84

15. Criee CP, Sorichter S, Smith HJ, Kardos P, Merget R, Heise D, et al. Body plethysmography--its principles and clinical use. Respir Med. 2011;105(7):959-71

16. Wanger J, Clausen JL, Coates A, Pedersen OF, Brusasco V, Burgos F, et al. Standardisation of the measurement of lung volumes. Eur Respir J. 2005:26(3):511-22.

17. Macintyre N, Crapo RO, Viegi G, Johnson DC, van der Grinten CP, Brusasco $V$, et al. Standardisation of the single-breath determination of carbon monoxide uptake in the lung. Eur Respir J. 2005;26(4):720-35.

18. Mahler DA, Wells CK. Evaluation of clinical methods for rating dyspnea. Chest. 1988;93(3):580-6.

19. Jones PW, Harding G, Berry P, Wiklund I, Chen WH, Kline Leidy N. Development and first validation of the COPD assessment test. Eur Respir J. 2009;34(3):648-54

20. Podsiadlo D, Richardson S. The timed "up \& go": a test of basic functional mobility for frail elderly persons. J Am Geriatr Soc. 1991;39(2):142-8.

21. ATS Committee on Proficiency Standards for Clinical Pulmonary Function Laboratories. ATS statement: guidelines for the six-minute walk test. Am J Respir Crit Care Med. 2002;166(1):111-7.

22. Meguro M, Barley EA, Spencer S, Jones PW. Development and validation of an improved, COPD-specific version of the St. George respiratory questionnaire. Chest. 2007;132(2):456-63.

23. Yoshizawa T, Okada K, Furuichi S, Ishiguro T, Yoshizawa A, Akahoshi T, et al. Prevalence of chronic kidney diseases in patients with chronic obstructive pulmonary disease: assessment based on glomerular filtration rate estimated from creatinine and cystatin C levels. Int J Chron Obstruct Pulmon Dis. 2015;10:1283-9.

24. Chen CY, Liao KM. Chronic obstructive pulmonary disease is associated with risk of chronic kidney disease: a Nationwide case-cohort study. Sci Rep. 2016;6:25855.

25. Gjerde B, Bakke PS, Ueland T, Hardie JA, Eagan TM. The prevalence of undiagnosed renal failure in a cohort of COPD patients in western Norway. Respir Med. 2012;106(3):361-6.

26. Incalzi RA, Corsonello A, Pedone C, Battaglia S, Paglino G, Bellia V, et al. Chronic renal failure: a neglected comorbidity of COPD. Chest. 2010;137(4):831-7.

27. Mapel DW, Marton JP. Prevalence of renal and hepatobiliary disease, laboratory abnormalities, and potentially toxic medication exposures among persons with COPD. Int J Chron Obstruct Pulmon Dis. 2013;8:127-34.

28. Schnell K, Weiss CO, Lee T, Krishnan JA, Leff B, Wolff $J$, et al. The prevalence of clinically-relevant comorbid conditions in patients with physiciandiagnosed COPD: a cross-sectional study using data from NHANES 19992008. BMC Pulm Med. 2012:12:26.

29. Baty F, Putora PM, Isenring B, Blum T, Brutsche M. Comorbidities and burden of COPD: a population based case-control study. PLoS One. 2013;8(5):e63285

30. Gaddam S, Gunukula SK, Lohr JW, Arora P. Prevalence of chronic kidney disease in patients with chronic obstructive pulmonary disease: a systematic review and meta-analysis. BMC Pulm Med. 2016;16(1):158.

31. Hayata A, Minakata Y, Matsunaga K, Nakanishi M, Yamamoto N. Differences in physical activity according to mMRC grade in patients with COPD. Int J Chron Obstruct Pulmon Dis. 2016;11:2203-8.

32. Park M, Yoon E, Lim YH, Kim H, Choi J, Yoon HJ. Renal hyperfiltration as a novel marker of all-cause mortality. J Am Soc Nephrol. 2015:26(6):1426-33.

33. Chronic Kidney Disease Prognosis C, Matsushita K, van der Velde M, Astor BC, Woodward M, Levey AS, et al. Association of estimated glomerular filtration rate and albuminuria with all-cause and 
cardiovascular mortality in general population cohorts: a collaborative meta-analysis. Lancet. 2010;375(9731):2073-81.

34. Zoccali C, Vanholder R, Massy ZA, Ortiz A, Sarafidis P, Dekker FW, et al. The systemic nature of CKD. Nat Rev Nephrol. 2017;13(6):344-58.

35. Weiner DE, Tighiouart H, Stark PC, Amin MG, MacLeod B, Griffith JL, et al. Kidney disease as a risk factor for recurrent cardiovascular disease and mortality. Am J Kidney Dis. 2004;44(2):198-206.

36. Fedeli U, De Giorgi A, Gennaro N, Ferroni E, Gallerani M, Mikhailidis DP, et al. Lung and kidney: a dangerous liaison? A population-based cohort study in COPD patients in Italy. Int J Chron Obstruct Pulmon Dis. 2017;12:443-50.

37. Fabbian F, De Giorgi A, Manfredini F, Lamberti N, Forcellini S, Storari A, et al. Impact of renal dysfunction on in-hospital mortality of patients with severe chronic obstructive pulmonary disease: a single-center Italian study. Int Urol Nephrol. 2016;48(7):1121-7.

38. Webster AC, Nagler EV, Morton RL, Masson P. Chronic kidney disease. Lancet. 2017;389(10075):1238-52.

39. Covic A, Vervloet M, Massy ZA, Torres PU, Goldsmith D, Brandenburg V, et al. Bone and mineral disorders in chronic kidney disease: implications for cardiovascular health and ageing in the general population. Lancet Diabetes Endocrinol. 2018;6(4):319-31.

\section{Publisher's Note}

Springer Nature remains neutral with regard to jurisdictional claims in published maps and institutional affiliations.

Ready to submit your research? Choose BMC and benefit from:

- fast, convenient online submission

- thorough peer review by experienced researchers in your field

- rapid publication on acceptance

- support for research data, including large and complex data types

- gold Open Access which fosters wider collaboration and increased citations

- maximum visibility for your research: over $100 \mathrm{M}$ website views per year

At BMC, research is always in progress.

Learn more biomedcentral.com/submissions 